\title{
An Investigation on the Anthropometric Profile and Its Relationship with Physical Performance of Adolescent Indian Swimmers - A Comparative Study
}

\author{
Chandra Prabha Jeyapal ${ }^{1}$, Praveen.S.Prakash ${ }^{2}$, Sundarprakash Sivalingam ${ }^{3}$, \\ ${ }^{1}$ Senior Lecturer in Physiology, Department of Physiology, Asia Metropolitan University, Johor Bahru, \\ Malaysia. \\ ${ }^{2}$ Student, Sports science, Sri Ramachandra Medical College, Chennai. \\ ${ }^{3}$ Associate Professor in Surgery, Melaka Manipal Medical College, Melaka, Malaysia
}

\begin{abstract}
The relationship between the anthropometric measurements and swimming performance is always a controversial topic. This study was designed to examine the relationship between the selected anthropometric measures of the body segments and the 100 mts swimming performance in the adolescent swimmers belonging to Chennai. Thirty five swimmers $(N=35)$ aged between 15 and 18 and matched controls from Chennai participated in the study. The 100 meters free style sprinting test was conducted and six anthropometric measurements, including the height, weight, chest circumference, mid-arm circumference, waist circumference and mid-thigh circumference, were taken. Pearson correlation analysis found that there was no significant relationship between the 100-meter freestyle sprinting performance and the selected anthropometric variables $(p>0.05)$. The results suggested that the selected anthropometric variables were predictors of sprinting performance but when compared with the anthropometric measurements of the controls significant difference in certain measurements were seen. The better timings recorded amongst swimmers had a correlation to their anthropometric measurements. The best linear correlation was found between body height and swimming performance.
\end{abstract}

\section{Introduction}

The aquatic sport of swimming is based on the human act of swimming, that is, locomotion in water by self-propulsion, with the goal of completing a given distance in the shortest amount of time. In some competitions swimming is for the enhancement of endurance or precedence rather than speed, such as crossing a long distanced channel or other stretch of open water. The sprints referred to short and high intensive events required high anaerobic capacity .Indeed, the acquisition of speed is critical for the majority of sports. In the event of track athletics, 100-meter freestyle sprinting race was probably the most impressive event in worldwide competition. The praise of being the fastest person in the world could be claimed by the world-record holder because of the sheer speed of this race. People all over the countries strive to complete in the international events, such as the Olympics game since 1896. However, we could seldom find Indian or even Asian on the final of sprinting events. There were numerous studies investigating the inborn characteristics of athletes determined by ethnicity. Swimming performance depends on optimizing propulsion and minimizing opposing factor-drag. Factors that contribute to this drag include the anthropometric measurements and body composition. Researchers investigated the proportionality characteristics of Olympic athletes in which the gender, ethnic and particular event influences on the physique of the athlete were studied. It was found that Black athletes tended to have proportionally longer arms, longer tibial length and larger thigh girth than the White athlete. Therefore, anthropometric measures have been identified to be significant factors affecting sports performance.

Sprinting, however, has shown limited percentage of improvement that can be made in other athletic events through prospering technical skills, strength and endurance. Therefore, identifying certain natural advantages of potential athletes is inevitable. Despite numerous researches and findings of identifying the factors of sprinting, it is a crucial question whether anthropometric variable of lower and upper limbs, including length, circumference and ratio are influential to sprinting performance. The purpose of this study was to examine the relationship between selected anthropometric measures of lower limbs and the sprinting performance of the 100 metre freestyle sprinting performance.

\section{LACUNAE}

Many studies have been reported in the previous times regarding the contribution of anthropometric measurements to sports. Most of them have been conducted in the foreign population. Very few studies have been conducted in the Indian population. Our study has been done specifically on the swimmers as very few studies have been conducted on the adolescent Indian swimmers. 
An investigation on the anthropometric profile and its relationship with physical performance of ..

AIM AND OBJECTIVES

The aim of the study is to establish a relationship between anthropometric profile and physical performance of adolescent Indian swimmers.

The objectives are:

1. Measurement of stature.

2. Measurement of body weight.

3. Measurement of mid-arm circumference.

4. Measurement of chest circumference.

5. Measurement of mid-thigh circumference.

6. Measurement of waist circumference.

7. Timing of 100 metres freestyle sprinting performance.

\section{MATERIAL AND METHODS}

The method of this study was divided into the following sections:
(a) Selection of subjects;
(b) Study design;
(c) Testing procedures; and
(d) Data

\section{Selection of Subjects}

Inclusion criteria

Age: $15-18$ yrs

Study Group: Under formal training in swimming for not less than 1 year. $n=35$

Controls: Not under formal training in swimming. $n=70$

\section{Exclusion criteria}

Cardio-respiratory illness.

Endocrine disorders.

Participation in any other form of sport.

Intake of steroids.

Intake of performance boosters like creatin or androgenic precursors.

The study included a total of 105 subjects aged between 15 and 18 years. Participants were fully informed of the possible risks and stresses associated with the test and signed consent forms prior to participation. Written consents were obtained from parents also. They had to participate in the 100-meter freestyle sprint and undertake selected anthropometric measures.

\section{Methods}

The study group was selected from the various swimming pools located at Chennai. Prior to the study meetings were held to explain the participants and their parents the aim of the study and its importance. Those who volunteered were chosen with strict adherence to the inclusion and exclusion criteria. The coaches were also informed duly. The same protocol was followed with the controls and the meetings (PIC:1) were held at SethuBhaskara Matriculation School. Written consent from the participants and parents were obtained.

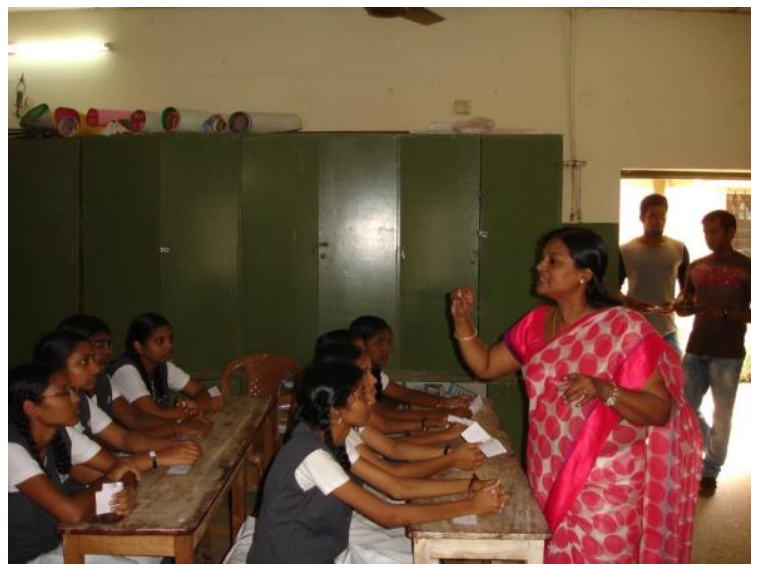

PIC 1: Meeting with the controls 
An investigation on the anthropometric profile and its relationship with physical performance of ..

Subjects were instructed to avoid vigorous exercise for at least 48 hours and consume their normal pretraining diet before the test session. All the selected anthropometric measurements were taken by the pool side. The 100-meter freestyle sprinting was then taken in various swimming clubs. The controls also participated in the performance testing. 40 volunteers out of 70 controls who had just the knowledge of swimming but no professional training were tested for $100 \mathrm{mts}$ freestyle sprinting performance. Standard anthropometric instruments were suggested by Norton et al. (1996) and were supported by the International Society for the Advancement of Kinanthropometry (ISAK).

\section{Testing Procedures}

The selected anthropometric measures were conducted by the pool side. The length and circumferences measurements were taken on the right side of the body. Every length and circumference variables was taken two times by the measurer, and the mean value was recorded for calculation. The advantage of taking multiple measurements was that random errors would tend to cancel out when the mean or median was used (Pederson \& Gore, 1996).

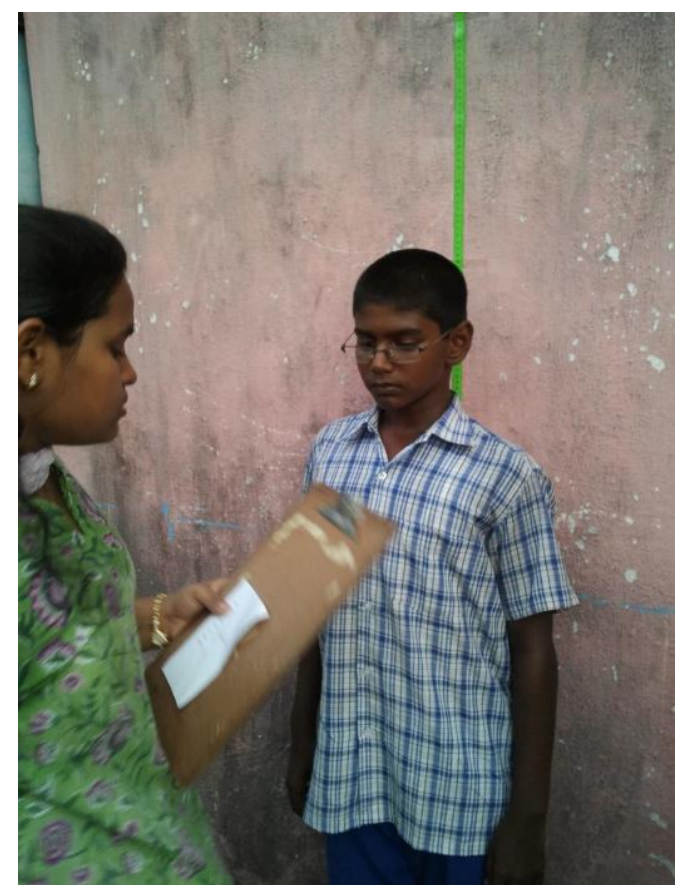

PIC 2: Measurement of height in swimmers

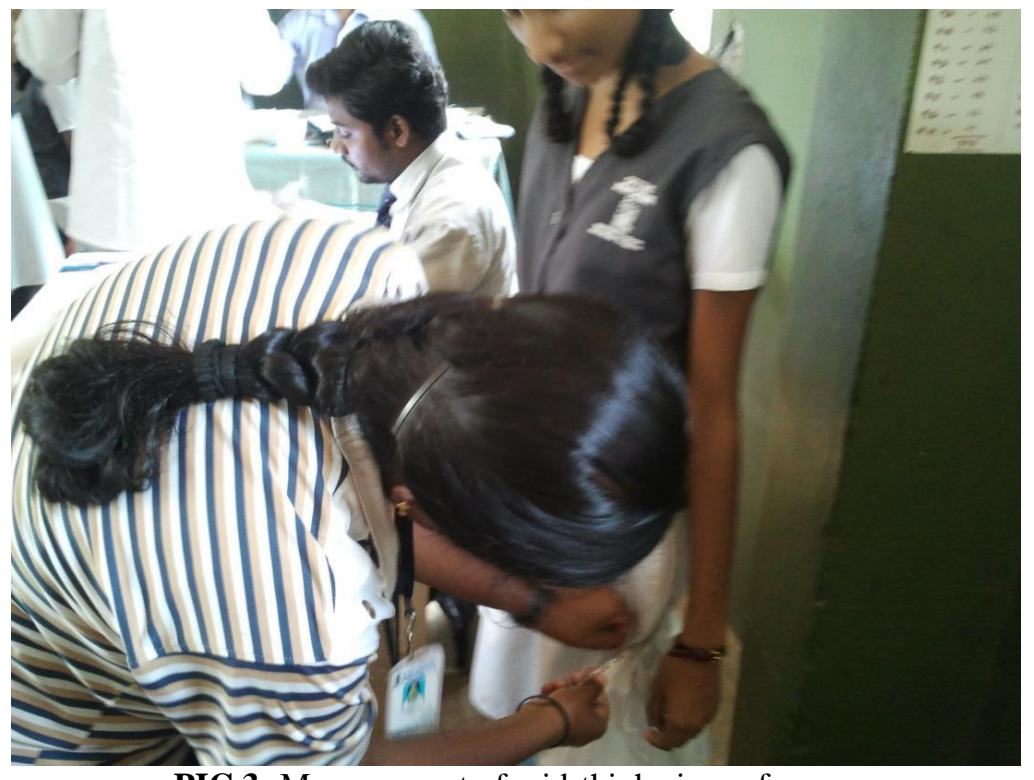

PIC 3: Measurement of mid-thigh circumference 


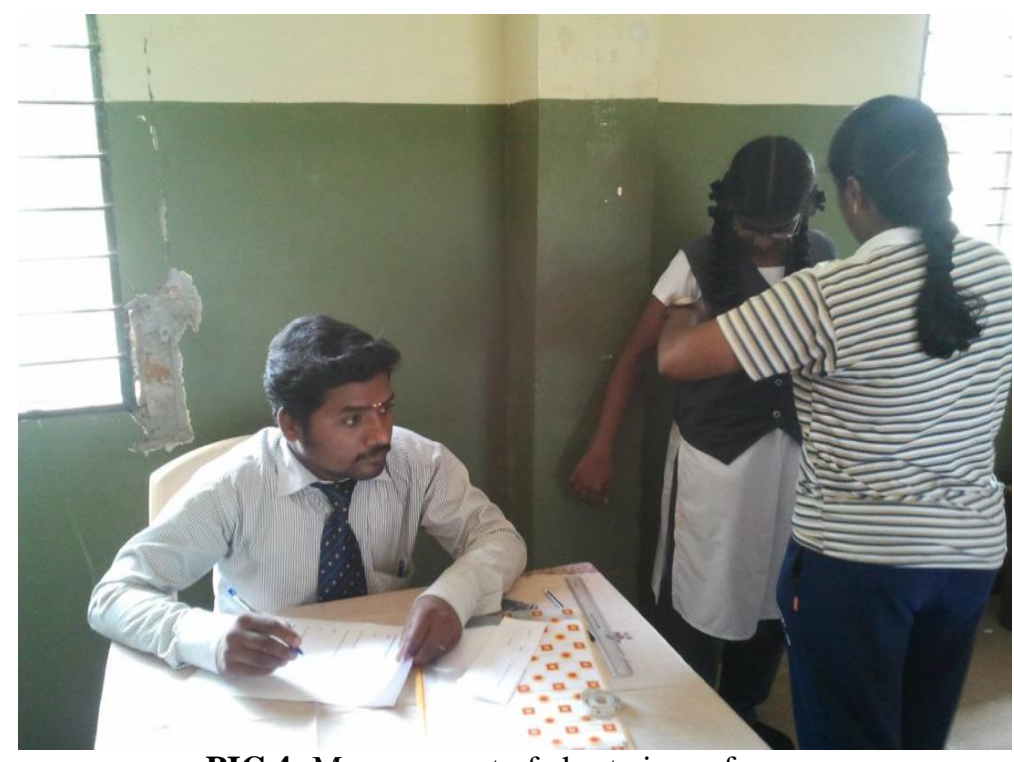

PIC 4: Measurement of chest circumference

The anthropometric measurements for the control group were recorded in the school premises after due permission from school authorities.

After all the anthropometric measurements were taken, subjects were asked to undergo a standardized warm-up, stretching routine, the 100-meter freestyle sprint and finally the cool down activity.

\section{Measurement of stature}

In this test, a stadiometer was used to check for height (Norton et al., 1996). The subjects were without footwear. Standing erect, subjects placed their feet flat on the floor with their heels together. While looking straight ahead, their arms should be placed naturally aside both thigh with the pales facing inwards. The posterior part of the body, including the head, scapula, and buttocks were touching to the wall. The reading was taken to the nearest $0.1 \mathrm{~cm}$.

\section{Measurement of body weight}

An electronic weighing scale was suggested by Norton et al. (1996) to measure the body weight. As the body weight would fluctuate during different time of the day, all the readings were taken at the same time of a day (Norton et al., 1996). The subjects dressed in minimal clothing and barefoot, got on to the middle of the scale with the weight distributed evenly between the feet. The measurement was taken with the participant standing erect with the looking straight ahead. The body weight was measured to the nearest $0.1 \mathrm{~kg}$.

\section{Measurement of thigh circumference (mid-thigh)}

The positioning of the tape for each specific circumference is important to ensure validity and reliability (Callaway et al., 1988). The thigh circumference was taken on the right leg perpendicular to the long axis of the thigh. The subject stood erect with the feet slightly apart and mass distributed evenly on both feet. The reading was measured at the level midway between the trochanter and tibial condyle (Norton et al., 1996), to the nearest $0.1 \mathrm{~cm}$.

\section{The 100-meter freestyle sprinting protocol}

The subjects were required to perform prior exercise including warm-up by jogging, stretching, moderate- to high-intensity striding and sprinting activities. The subject began from a starting position by lowering the centre of gravity and leaning slightly forward, ready to react to the command "Ready" and "Go". The timer stood at the finish line, at a location suitable for viewing the subject's start and finish. The starting helper stood at the starting line, gave the command "Go" while sweeping down his/ her arm. The timer started the stopwatch at the moment the sweeping down movement was seen. The subject would be encouraged to run in their maximal speed continuously through the finish line. The timer stopped the watch when the subjects' chest passed through the finish line, the time would be recorded to 2 decimal places. The sprinter performed a proper analysis. The timer stopped the watch when the subjects' chest passed through the finish line, the time would be recorded to 2 decimal places. The sprinter performed a proper cool-down by repeating the routine similar to the warm-up and by stretching the legs periodically afterwards to prevent delayed onset muscle soreness (DOMS). 
An investigation on the anthropometric profile and its relationship with physical performance of ..

Statistical analysis was performed with Graph pad prism version 5. Mean and standard deviations were calculated for each variable. Selected anthropometric variables were correlated with sprinting times. Multiple regression analysis was used to identify the performance relevant predictor anthropometric variables. For all statistical tests, an alpha level of $\mathrm{p}<0.05$ level of significance was used. T-test was performed to compare the difference in proportionalities of all the variables in both groups and $\mathrm{p}$ value was obtained. Anova was perfomed to test the difference in variances.

\section{Analysis of Data And Results}

The descriptive statistics of the control and study group's physical characteristics are shown in Table 1\&2:

TABLE 1 : General statistics for controls

\begin{tabular}{|l|l|l|l|l|l|l|l|}
\hline & wt & ht & mac & cc & mtc & waist & Timings(n=40) \\
\hline Mean & 53.921 & 161.014 & 24.907 & 86.35 & 47.342 & 73.371 & 103.252 \\
\hline SD & 10.799 & 7.248 & 3.232 & 6.783 & 6.541 & 9.007 & 12.781 \\
\hline Variance( SD) & 116.62 & 52.543 & 10.451 & 46.017 & 42.793 & 81.135 & 163.36 \\
\hline Population SD & 10.721 & 7.196 & 3.209 & 6.734 & 6.494 & 8.942 & 12.62 \\
\hline Variance( Population SD) & 114.954 & 51.792 & 10.302 & 45.359 & 42.182 & 79.976 & 159.272 \\
\hline Std error & 1.29 & 0.87 & 0.38 & 0.81 & 0.78 & 1.076 & 1.326 \\
\hline
\end{tabular}

TABLE 2 : General statistics for swimmers:

\begin{tabular}{|l|l|l|l|l|l|l|l|}
\hline & wt & ht & mac & cc & mtc & waist & Timings(n=35) \\
\hline Mean & 60.242 & 168.386 & 27.243 & 92.557 & 49.457 & 72.614 & 56.44 \\
\hline SD & 9.713 & 8.404 & 2.25 & 6.171 & 4.045 & 7.077 & 1.299 \\
\hline Variance( SD) & 94.358 & 70.634 & 5.064 & 38.085 & 16.358 & 50.089 & 1.788 \\
\hline Population SD & 9.574 & 8.283 & 2.218 & 6.082 & 3.986 & 6.976 & 1.318 \\
\hline Variance( Population SD) & 91.662 & 68.616 & 4.919 & 36.997 & 15.891 & 48.658 & 1.737 \\
\hline Std error & 1.64 & 1.42 & 0.38 & 1.04 & 0.68 & 1.196 & 0.226 \\
\hline
\end{tabular}

TABLE 3 : t-test results(2-tailed):

\begin{tabular}{|l|l|l|l|l|l|l|l|}
\hline & wt & ht & mac & cc & mtc & waist & timings \\
\hline $\mathrm{p}$ value & 0.00429 & 9.6909 & 0.00022 & 0.0032 & 0.00314 & 0.66491 & 0.0062 \\
\hline
\end{tabular}

The general statistics for the selected anthropometric measurements was made for both the groups as seen in table $1 \& 2$. The tests revealed a significant difference in height, chest circumference, mid-thigh circumference and weight. The 100metres swimming performance was also assessed and the timings noted, the $\mathrm{p}$ value being less than 0.05 . The MS difference in the mid-thigh circumference being the smallest indicates less deviation between the controls and the swimmers. The $\mathrm{p}$ value (Table 3 ) for t-test in the weight, mid-arm circumference, mid-thigh circumference, chest circumference and timings being less than 0.001 providing strong evidence against null hypothesis. The comparative charts depict the difference in the Mean, SD, Variance in the anthropometric measurements and 100 meters performance timings between the controls and the swimmers.

\section{Comparative charts:}

Figure 1: comparative chart of weight

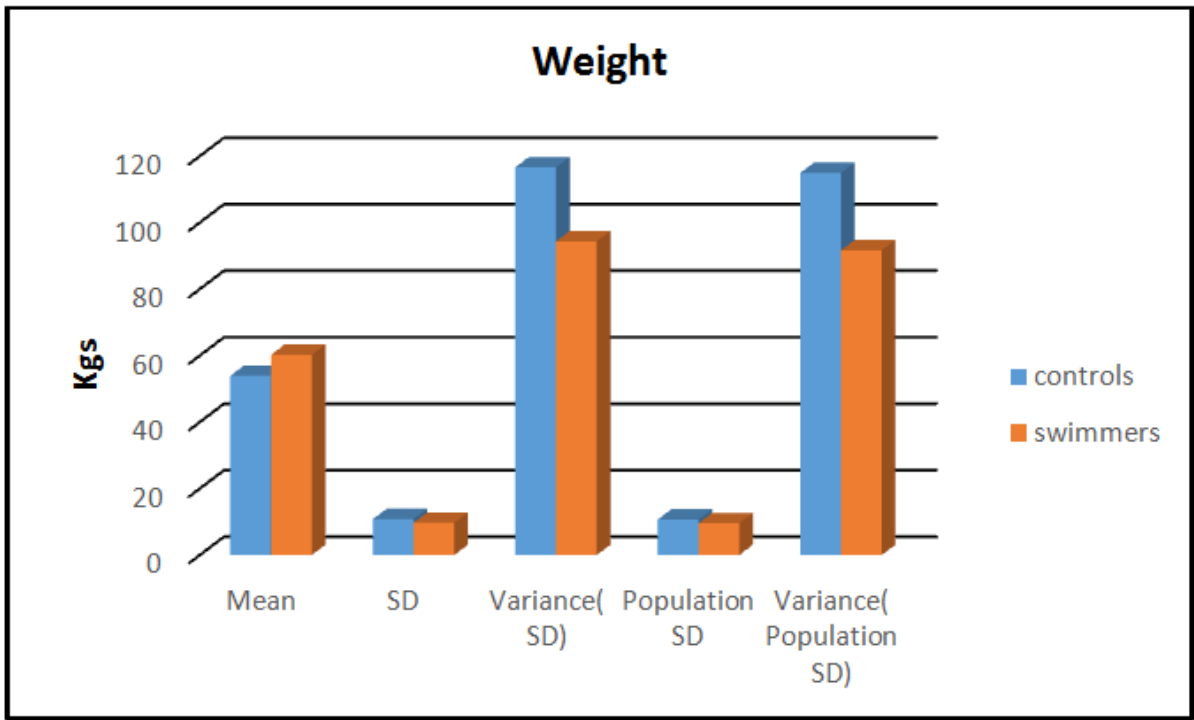

Fig 1: Comparative chart of weight 
Figure 2: comparative chart of height

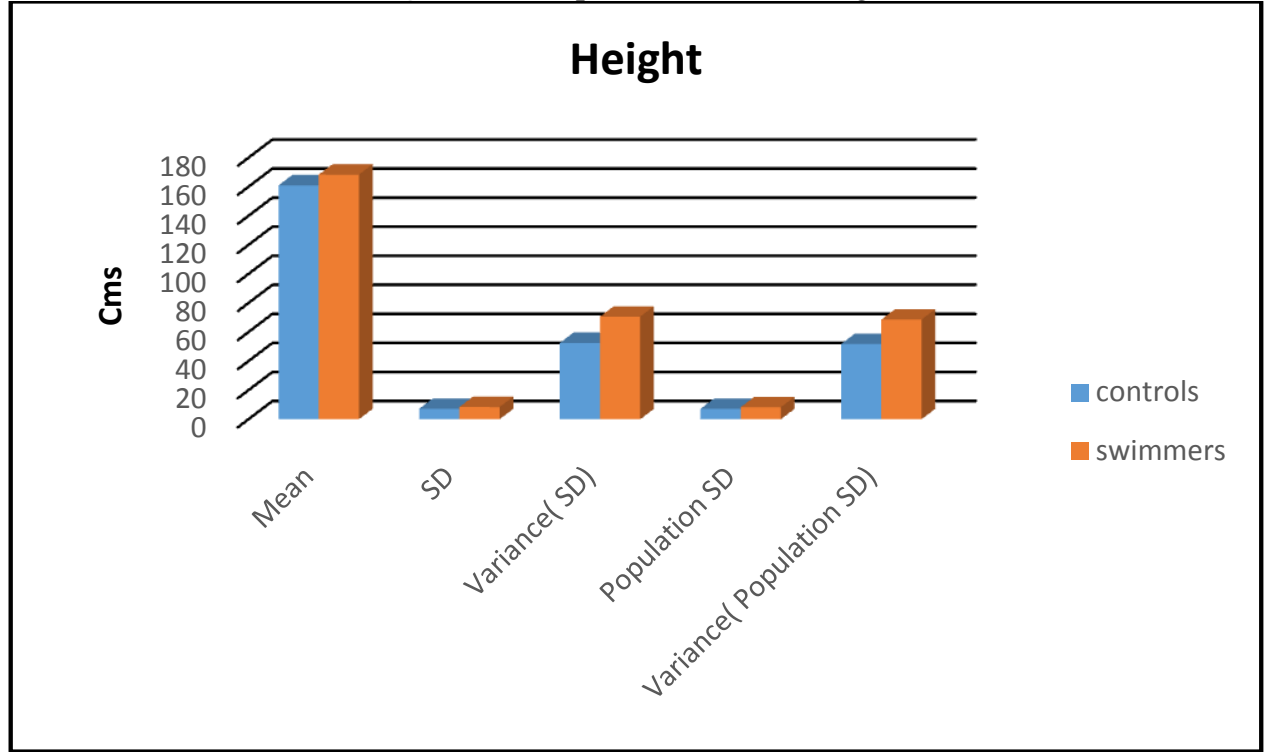

Fig 2: Comparative chart of height

Figure 3: comparative chart of mid-arm circumference

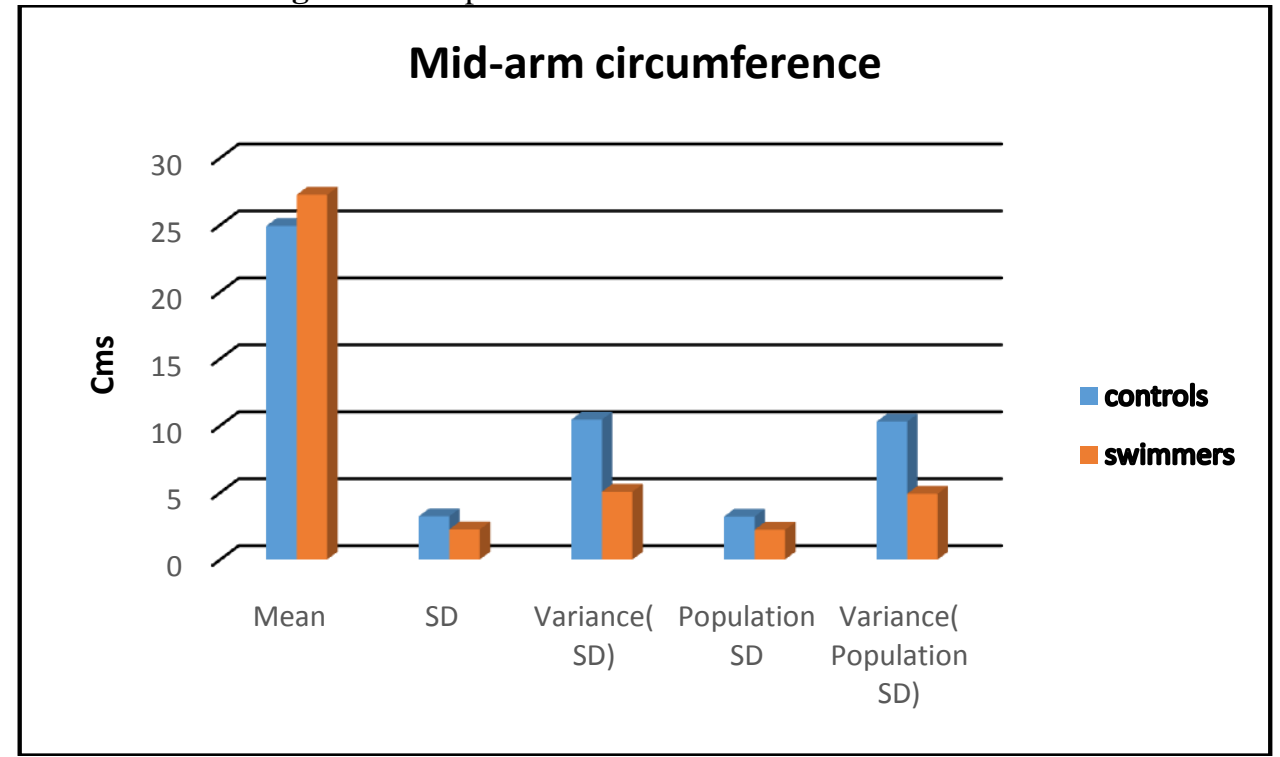

Fig 3: comparative chart of mid-arm circumference

Figure 4: comparative chart of chest circumference

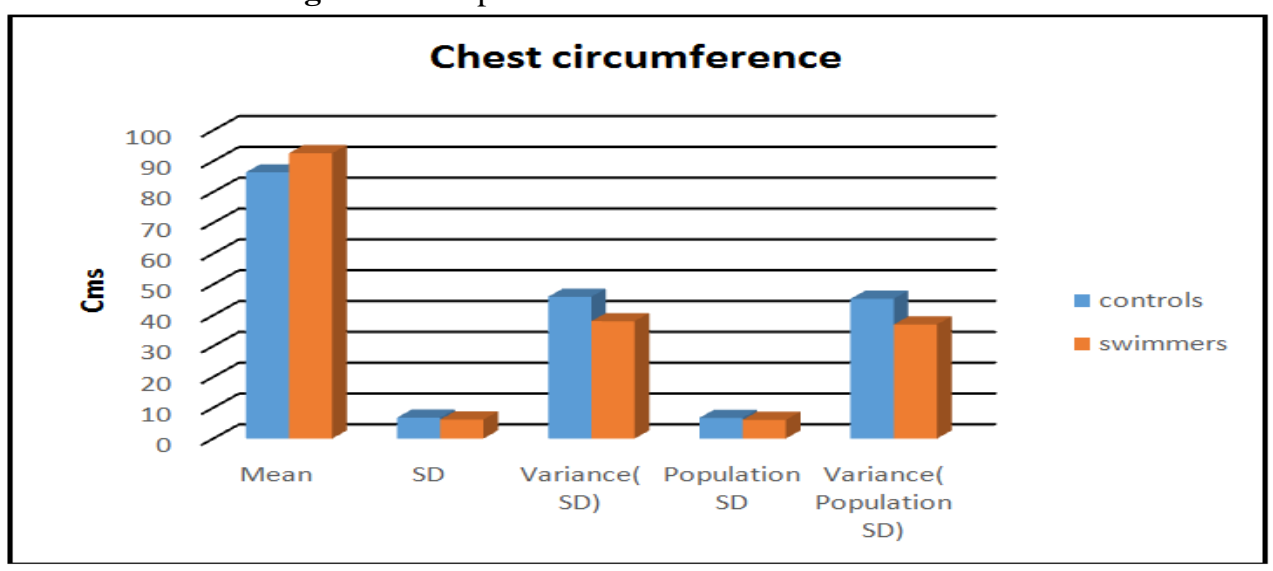

Fig 4: comparative chart of chest circumference 
Figure 5: comparative chart of mid-thigh circumference

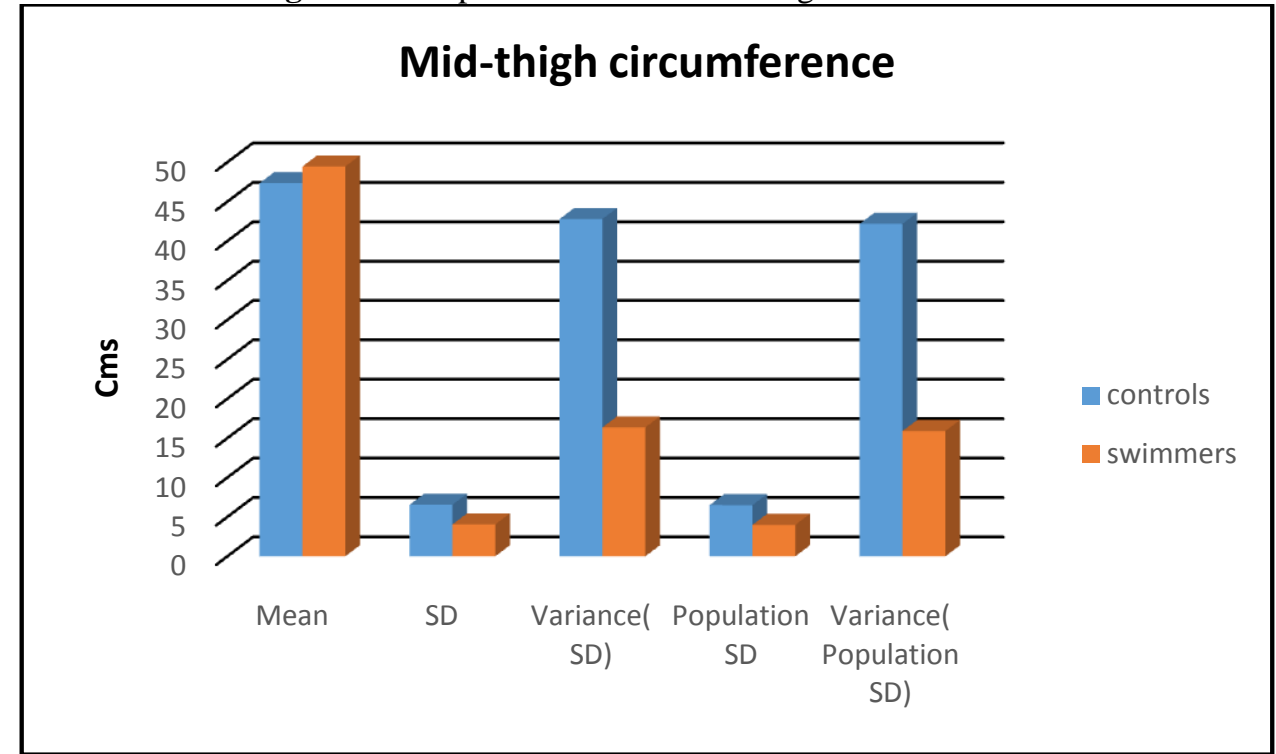

Fig 5: comparative chart of mid-thigh circumference

Figure 6: comparative chart of waist circumference

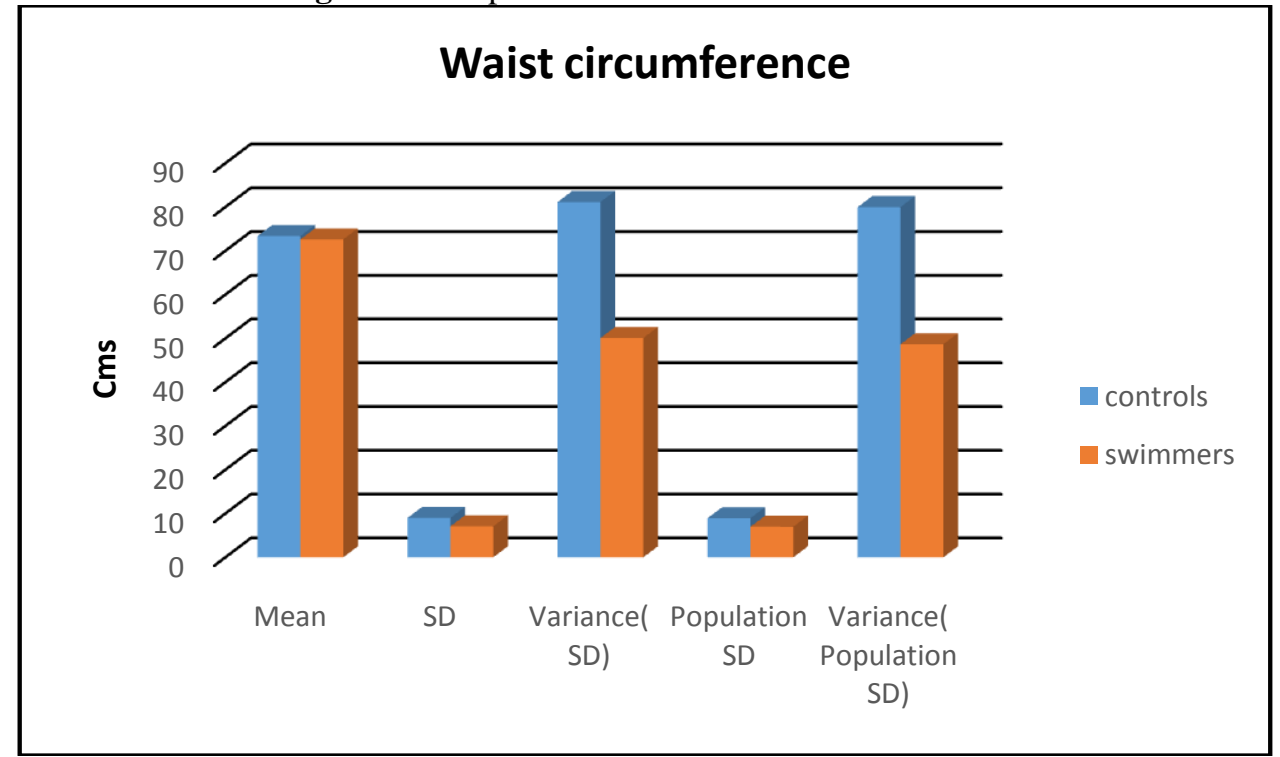

Fig 6: comparative chart of waist circumference

Figure 7: comparative chart of $100 \mathrm{mts}$ timings

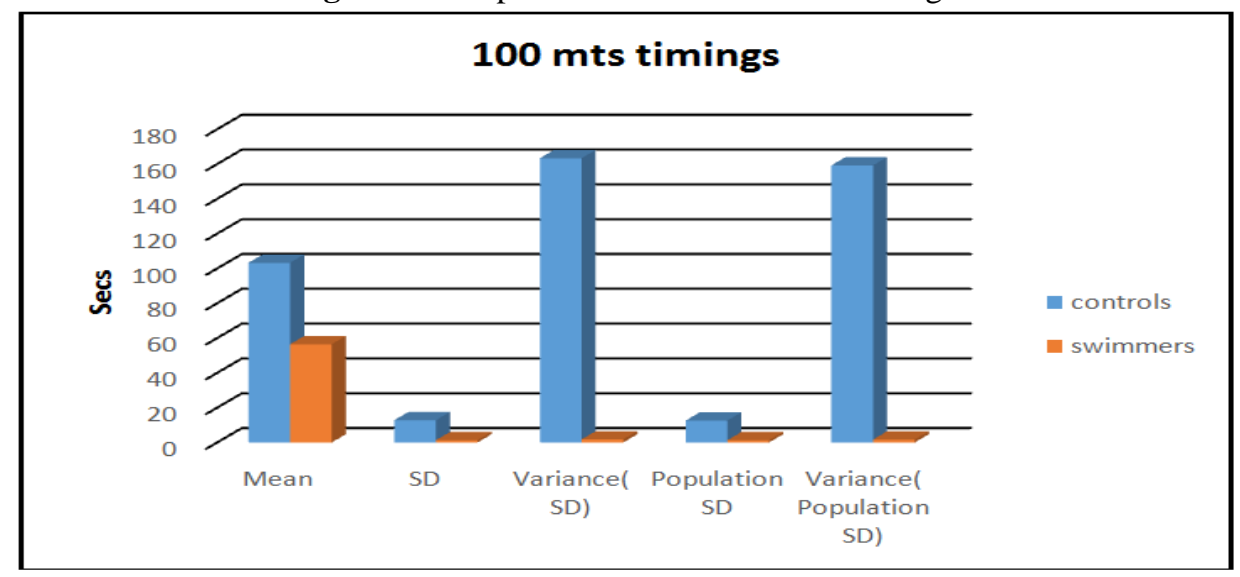

Fig 7: comparative chart of $100 \mathrm{mts}$ timings 


\section{Discussion}

The purpose of this study was to examine the relationship between selected anthropometric measures and the 100 meters sprinting performance in the adolescent age group Indian students. Several researchers have studied the morphologic and anthropometric characteristics of different populations of elite swimmers. One of the most extensive studies is Kinanthropometry in Aquatic Sports (A Study of World Class Athletes). This study, so-called KASP Study, was conducted during the 6th FINA World Championships in Perth (Australia) in 1991. In this study, body size, body fat, shape and proportionality of 922 elite aquatic athletes including 170 female swimmers and 231 male swimmers were measured by high quality and criterion anthropometries.

Although there are different predictors of elite swimming performance (physiological, mental, and physical), anthropometric assessment is one of the vital parameters, especially in talent selection programs. Anthropometry is the science of human body measurements including skinfolds, lengths, diameters and circumferences.

A study conducted by Galadas.ND et al in 2005 among Greek adolescent swimmers found a significant relationship of anthropometric measurements to 100 metres sprint performance $(r=0.22-0.31) p$ is lesser than 0.05. Similar association was found in our study too. Though the morphological variables are significantly better predictor of a swimming result in a sample of swimmers than in non-athletes, they would have more weightage in a comparative study within an athlete group. Study by Sekulic in 2007 observed that anthropometric variables predict the swimming results more significantly in the trained sample compared to non-athletic controls. This study had lots of similarities to ours.

From the results presented in the table $1 \& 2$ it is obvious that anthropometric variables predict swimming results more significantly in the trained sample (athletes), comparing to non-athletes. Generally, it is not hard to explain.

The sample of subjects we used in our study has a very similar swimming technique (e.g. their technique is excellent). In other words, if the swimming technique is not a component which differentiates the subjects in their swimming results - the greater part of the variance remains to be explained by other dimensions. In our case it allowed determination of the anthropometrics' influence on the swimming achievement. Basically, the most significant linear anthropometric predictor of swimming performance is $\mathrm{BH}$. The linear relationship between $\mathrm{BH}$ and swimming performance can be explained simply. A more pronounced $\mathrm{BH}$ defines longer extremities, while longer extremities allow one to: perform fewer arm strokes for the same distance, but also to achieve a higher moment of force (MF) in the single stroke because of the law of levers $(M F=F . a)$. In our case, the $» F \ll$ is force applied during a single arm stroke, and $» a \ll$ is the distance between a single joint and connection-point of the active muscles on the bone (lever). Naturally, » $a$ « increases with $\mathrm{BH}$, which is followed by an increase in MF, all allowing one to perform more effectively in FS. Of course, all said can be expected only if $\mathrm{BH}$ is followed by $\mathrm{BW}$, in other words - muscle mass (MM) as a generator of force.

Therefore, the 1st hypotheses of our work is already practically confirmed since the morphological variables are a significantly better predictors of the swimming result in the sample of swimmers (trained athletes), than in previously studied8 non-athletes Our results were consistent with previously reported values for elite adolescent competitive swimmers. Previous research on anthropometry in athletes has suggested that certain physical characteristics such as height and limb length are associated with higher levels of performance in a given population of athletes.

Although previous research has been published on the anthropometric characteristics of elite swimmers and on anthropometric and other physical characteristics related to performance, the current research has examined a larger participant pool, has included both male and female athletes, and has included results from a broader range of ages. This view is also supported by another author Gregory D.Wells, who in his study, "Normal physiological characteristics of elite swimmers" analysed the anthropometric measurements and observed a positive correlation between selected anthropometric measurements and performance.

In fact, Prof. Carter and his colleagues conducted the Montreal Olympic Games Anthropological Project (MOGAP Study). In this study, 44 male and 33 female Olympic swimmers were assessed anthropometrically. He too found that body height was a major contributor to the swimming performance.

\section{Conclusion}

So it was concluded that the following selected anthropometric measurements such as height, mid-arm circumference, chest circumference and waist circumference definitely contributed to swimming performance. The better timings recorded among swimmers had a correlation to their anthropometric measurements when compared to that of controls. The best linear correlation was found between body height and swimming performance. 
An investigation on the anthropometric profile and its relationship with physical performance of ..

\section{Recommendations for Further Study}

Further recommendations for this study are as follows:

1. A larger sample size should be carried out in order to conduct a more representative research.

2. The sample should be obtained from subjects with various exercise background, including the elite athletes, recreational athletes and non-athletes.

3. Sprinting distance other than 100 meters could be included as the dependent variables. Other swimming styles like butterfly, breast stroke and back stroke could be included. The selected measures may be found to be predictors of the swimming performance at various distances with the same independent variables.

5. To acquire a more comprehensive relationship between the sprinting performance and the anthropometric measurements, others factors such as shoulder width, hip joint flexibility and skinfold thicknesses may be identified as predictors of swimming performance.

6. To ensure a more precise testing result in the sprinting test, the timer and the helper should be trained beforehand.

\section{References}

[1]. Abe, T., Fukashiro, S., Harada, Y., \& Kawamoto, K. Relationship between sprint performance and muscle fascicle length in female sprinters. Journal of Physiological Anthropology and Applied Human Science, 141-147 (2001).

[2]. Amusa, L. O., \&Toriola, A. L. Leg power and physical performance measures of top national track athletes. Journal of Exercise Science and Fitness, 1(1), 61-67(2003).

[3]. Bale, P., Bradbury, D., \& Colley, E. Anthropometric and training variables related to $10 \mathrm{~km}$ running performance. Journal of Sports Medicine, 20(4), 170-173 (1986).

[4]. Bao, J. W. Research on running character of Usain Bolt. Bulletin of Sport Science, 17(8), 23-24(2009).

[5]. Cissik, J. M. Technique and speed development for running. NSCA's Performance Training Journal, 1(8), 18-21 (2002).

[6]. Elliott, B. C., \&Blanksby, B. A. Optimal stride length considerations for male and female recreational runners. British Journal of Sports Medicine, 13, 15-18 (1979).

[7]. Greenhaff, P.L., Nevill, M. E., Soderlund, K., Bodin, K.,Boobis, L. H., Williams, C., et al. The metabolic responses of human type I and II muscle fibers during maximal treadmill sprinting. Journal of Physiology, 478(1), 149-155 (1994).

[8]. Hunter, J. P., Marshall, R. N., \&Mcnair, P. J. Interaction of step length and step rate during sprint running. Medicine \& Science in Sports \& Exercise, 261-271 (2004).

[9]. Kong, P. W., \&Heer, H. Anthropometric, gait and strength characteristics of Kenyan distance runners. Journal of sports Science and Medicine, 7, 499-504(2008).

[10]. Knechtle, B., Baumann, B., Knechtle, P., Wirth A., \&Rosemann, T. A comparison of anthropometry between ironman triathletes and ultraswimmers. Journal of Human Kinetics, 24, 57-64 (2010).

[11]. Knechtle, B., Knechtle, P., Andonie, J. L., \& Kohler, G. Influence of anthropometry on race performance in extreme endurance triathletes: World Challenge Deca Iron Triathlon 2006. Journal of Sports Medicine, 41, 644-648 (2007).

[12]. Knechtle, B., \& Kohler, G. Influence of anthropometry on race performance in ultra-endurance triathletes in the longest triathlon in North America. InternationalSportMed Journal, 8(2), 87-96 (2007).

[13]. Kukolj, M., Ropret, R., Ugarkovic, D., \&Jaric, S. Anthropometric, strength, and power predictors of sprinting performance. Journal of Sports Medicine and Physical Fitness, 39(2), 120-122 (1999).

[14]. Maughan, R. J., \&Nimmo, M. A. The influence of variations in muscle fiber composition on muscle strength and cross-sectional area in untrained males. Journal of Physiology, 351, 299-311 (1984).

[15]. Meckel, Y., Atterbom, H., Grodjinovsky, A., Ben-Sira, D., \&Rotstein, A. Physiological characteristics of female 100 metre sprinters of different performance levels. Journal of sports medicine and physical fitness, 35 (3), 169-175 (1995). 